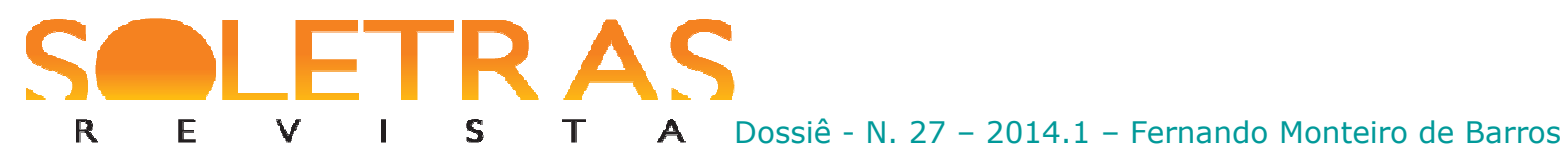

\title{
Do castelo à casa-grande: o “Gótico brasileiro”, em Gilberto Freyre
}

Fernando Monteiro de Barros ${ }^{1}$

Universidade do Estado do Rio de Janeiro

Resumo: A partir da topografia do romance gótico inglês, expressa no castelo malassombrado, estabelecemos uma teoria do que seria possivelmente um "Gótico brasileiro", evidenciado no elemento topográfico da casa-grande segundo o constructo que dela faz o sociólogo pernambucano Gilberto Freyre em Casa-grande \& senzala, no qual encontramos fortes traços de literariedade. As recentes teorias acerca do Gótico sulista norte-americano, que estabelecem a herança escravocrata como seu principal elemento, contribuem para nossa tese sobre a casa-grande em Freyre, que, fantasmática e alegórica, afigura-se como verdadeiro espaço paratópico, em que o real da investigação sociológica mescla-se ao irreal do imaginário literário.

Palavras-chave: Gótico brasileiro. Tradição e modernidade. Fantasma e alegoria.

Parado o engenho, extintas as senzalas,

Sem mais senhor, existe inda a fazenda,

A envidraçada casa de vivenda

Entregue ao tempo com as desertas salas.

Se ali penetras, vês em cada fenda

Verdear o musgo e ouves, se acaso falas,

Soturnos ecos e o roçar das alas

De atros morcegos em revoada horrenda.

Ama o luar, entretanto, essas ruínas.

Uma noite, horas mortas, de passagem

Eu a varanda olhava, quando vejo

À janela da frente, entre cortinas

De prata e luz, chegar saudosa imagem

E, unindo os dedos, atirar-me um beijo...

O soneto XVI do Terceiro Canto do grupo “Alma em Flor”, publicado por Alberto de Oliveira (2007, p. 180-1) no volume Poesias, $2^{a}$ Série, em 1912, transcrito acima, apresenta uma curiosa combinação do Brasil de certa tradição colonial/imperial com as marcas do imaginário da literatura gótica inglesa da segunda metade do século XVIII. Assim como

\footnotetext{
1 Fernando Monteiro de Barros é Doutor em Literatura Brasileira pela UFRJ e Professor de Literatura Brasileira da Faculdade de Formação de Professores da UERJ, em São Gonçalo, onde também atua no curso de Especialização em Estudos Literários. Atualmente desenvolve pesquisa sobre o Gótico e o Decadentismo na Literatura Brasileira. É membro pesquisador do Grupo de Pesquisa Estudos do Gótico (CNPq). E-mail: fernandobarros.letras@gmail.com. 


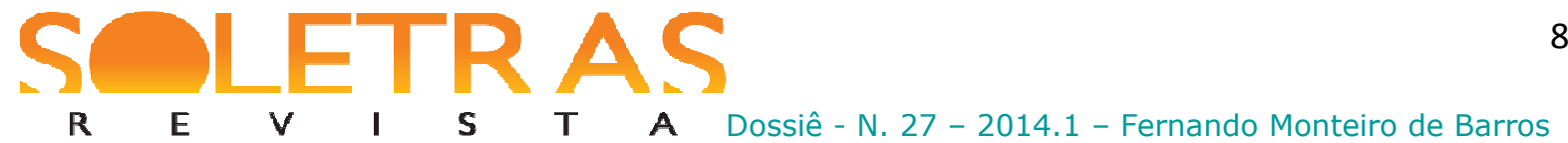

naquela modalidade literária o castelo em ruínas mal-assombrado assomava como representação de uma tradição arruinada - a do medievo com todo o seu substrato arcaico -, no soneto do nosso poeta parnasiano a casa-grande, em ruínas e habitada pelo fantasma que atira o beijo, igualmente comparece como representação de um passado extinto - no caso, o de nosso etos patriarcal, tão bem analisado por Gilberto Freyre em seu Casa-grande \& senzala. O Gótico tem sido, efetivamente, "um gênero extraordinariamente flexível que tem se adaptado e florescido em uma variedade de países ao longo de alguns séculos", segundo Bridget M. Marshall (2013, p. 3). Dentro dessa perspectiva trans-histórica, o presente trabalho tem por intuito apresentar algumas ocorrências do que decidimos denominar por Gótico brasileiro.

Embora a presença do Gótico na literatura brasileira já se faça perceber no próprio período romântico, principalmente nas obras de Álvares de Azevedo e Bernardo Guimarães, preferimos por ora concentrarmo-nos nas narrativas que tematizam a tradição patriarcal brasileira configurada na casa-grande arruinada. Para tal, escolhemos a obra Casa-grande \& senzala (1933), de Gilberto Freyre, cujo elemento topográfico principal, a casa-grande em ruínas, comparecerá mais tarde em narrativas da literatura brasileira que apresentam fortes traços do Gótico, como nos romances A menina morta (1954), de Cornélio Penna, $O$ desconhecido (1940) e Crônica da casa assassinada (1959), de Lúcio Cardoso.

O romance $O$ castelo de Otranto (1764), do autor inglês Horace Walpole, é o texto fundador da literatura gótica. Conforme sublinham David Punter e Glennis Byron, "se há algo como uma topografia geral do Gótico, então seu motivo central é o castelo", espaço labiríntico e arruinado habitado por espectros, ostentando uma "magnificência feudal, embora atormentada" (PUNTER; BYRON, 2004, p. 259). Bridget M. Marshall acrescenta que "os romances góticos britânicos extraem uma quantidade considerável de sua atmosfera atormentada e condenada da locação da ação", uma vez que "até o título $O$ castelo de Otranto deixa claro que o aspecto arquitetônico é essencial para a narrativa", já que o próprio castelo é "fonte de terror, ao representar poderosas estruturas econômicas e sociais que perduraram por várias gerações" (MARSHALL, 2013, p. 6).

Dentro dessa perspectiva topográfica como base da narrativa gótica, bem como do aspecto fantasmático de uma estrutura social derrotada e antiga convivendo no cenário da modernidade, alguns críticos literários norte-americanos propuseram uma subcategoria do que se conhece por American Gothic, ou Gótico norte-americano: a do Southern Gothic, ou, Gótico sulista, fortemente marcado pelo antigo etos senhorial e escravocrata do sul dos 


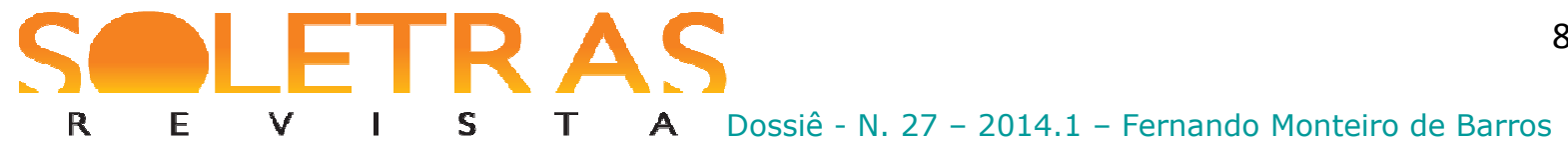

Estados Unidos, já que a história da escravidão permanece como seu pano de fundo principal (ELLIS, 2013, p. xx). De fato, várias narrativas norte-americanas de vampiros, como os romances de Anne Rice e a série de televisão True Blood (HBO, 2008-2014), se passam no "velho sul" (ELLIS, 2013, p. xxiii). Conforme afirma Bridget Marshall, a falta de castelos medievais no sul estadunidense é compensada pelas plantations, grandes propriedades senhoriais latifundiárias, dispersas pela paisagem e que ostentam vários sinais de decrepitude (MARSHALL, 2013, p. 6).

Nossa tese, aqui, é a de que o Gótico brasileiro segue os mesmos parâmetros do Gótico sulista norte-americano, já que o Brazilian Gothic, assim como o Southern Gothic, apresenta em suas narrativas o legado fantasmático de uma sociedade marcada pelo sistema escravocrata, conforme a afirmativa de Jay Ellis acima. Nas palavras de Bridget M. Marshall, cujas reflexões retomamos,

A plantation sulista [com sua casa-grande] funciona bem como substituta dos castelos góticos tradicionais devido à sua referência simbólica a uma aristocracia decaída. Assim como os castelos arruinados fazem alusão à perda de riqueza e poder de uma geração mais antiga, o estado arruinado da plantation sulista no período após a Guerra Civil americana refere-se à história da classe dos latifundiários, e, de fato, a todo o sul dos Estados Unidos de uma maneira geral. O espaço físico da casa-grande (assim como o do castelo) ecoa a natureza decaída dos habitantes com seus numerosos aposentos, faustosos no passado, mas agora deteriorados. Tanto as casasgrandes quanto os castelos remetem a um passado perdido... (MARSHALL, 2013, p. 7).

Nesta perspectiva, o romancista norte-americano William Faulkner (1897-1962) é, segundo afirmam David Punter e Glennis Byron (2004, p. 116), "por muitos considerado o progenitor deste subgênero intitulado Southern Gothic, que se apropria de elementos do Gótico tradicional, combinando-os com questões específicas do sul dos Estados Unidos”. Para muitos críticos, Faulkner apresenta uma

[...] versão goticizada do velho sul norte-americano, ao tratar dos temas da loucura, da decadência e do desespero, assim como as recorrentes pressões do passado sobre o presente, em particular com relação aos ideais perdidos de uma aristocracia sulista destituída e à continuidade dos conflitos raciais. (PUNTER; BYRON, 2004, p. 216-217).

De fato, um dos aspectos essenciais da literatura gótica é o da influência do passado (fantasmático, da tradição) sobre o presente (moderno e industrial).

Gilberto Freyre, em sua obra de estreia, salienta as similitudes entre o etos do sul dos Estados Unidos e o do passado senhorial do Brasil. Em seu prefácio à primeira edição de Casa-grande \& senzala, Freyre assinala que "a todo estudioso da formação patriarcal e da 


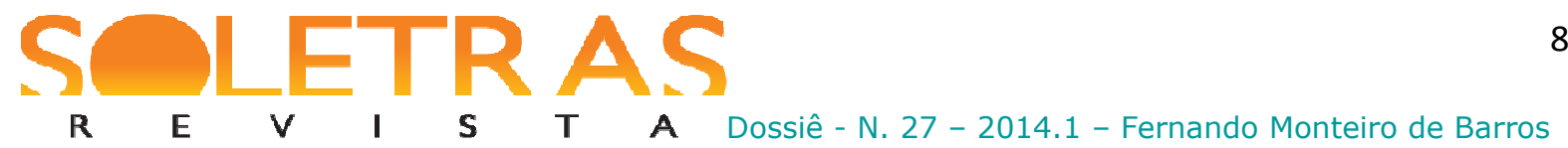

economia escravocrata do Brasil impõe-se o conhecimento do chamado "deep South" (FREYRE, 2002, p. 6), que é o "velho sul escravocrata" norte-americano, onde se destacam estados como "Louisiana, Alabama, Mississippi, as Carolinas, Virginia", que constituem, com efeito, uma "região onde o regime patriarcal de economia criou quase o mesmo tipo de aristocrata e de casa-grande; quase o mesmo tipo de escravo e de senzala que no norte do Brasil e em certos trechos do sul" (FREYRE, 2002, p. 6).

A obra de Freyre é, reconhecidamente, um importante marco no estudo sociológico da formação da civilização brasileira, mas, ao mesmo tempo, como apontamos acima, conjuga de forma curiosa à pesquisa antropológica uma literariedade no estilo. Como se sabe, os Formalistas Russos definiram literariedade como sendo "aquilo que torna determinada obra uma obra literária" (SCHNAIDERMAN, 1976, p. IX-X), a partir de seus elementos estéticos. Para muitos, o que Freyre faz é uma espécie de sociologia literária. Eduardo Portella afirma: "Gilberto é antes de tudo um escritor. Um ensaísta, um narrador" (PORTELLA, 2002, p. XXII), em cuja obra "ciência e arte se entrelaçam" (2002, p. XXIII), o que é ratificado por Luciana Stegagno Picchio: "as suas grandes obras sociológicas [...] são ainda calibradíssimas obras literárias: escritas em prosa tersa e cativante, em que o rigor científico se alia à calorosa simpatia pelo assunto tratado" (PICCHIO, 1997, p. 480). Edson Nery da Fonseca corrobora tal ponto de vista, ao frisar que "logo no prefácio à primeira edição do livro ele seduz o leitor com a linguagem e o estilo de um ensaísta literário: um ensaísta que se destacou tanto pelas imagens visuais e simbólicas como pelas enumerações" (FONSECA, 2002, p. 870). Massaud Moisés, por sua vez, reconhece em Casa-grande \& senzala um "estilo aliciante, não propriamente dum sociólogo, ao menos do sociólogo acadêmico", ressaltando que nesta obra "a arte literária [está] a serviço da ciência", já que "sem perda de rigor, o ensaísta esmera-se numa linguagem de inflexão oral, jornalística [...] que se lê com agrado, quase como se se percorresse um romance" (MOISÉS, 1989, p. 172-173). Também o crítico literário Antonio Candido percebe que, não só na obra de Freyre, como também em outras obras sociológicas dos anos 30, "a literatura permaneceu em posição-chave", já que "alguns dos produtos mais excelentes dessa época, no campo dos estudos sociais, como Casa-grande e senzala, Sobrados e mucambos, Raízes do Brasil, lhe são tributários, não apenas pelo estilo, mas principalmente pelo ritmo da composição e a própria qualidade da interpretação" (CANDIDO, 1967, p. 156-157). Candido reconhece que essa linha de ensaio funciona como "elemento de ligação entre a pesquisa puramente científica e a criação literária" (CANDIDO, 1967, p. 153), e ressalta que "antes, de Euclides da Cunha a Gilberto Freyre, a sociologia 


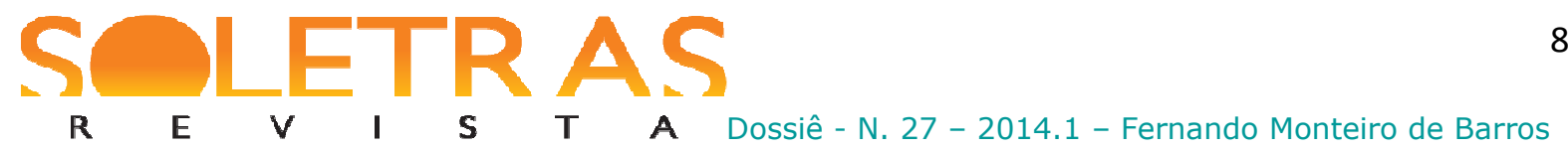

aparecia mais como 'ponto de vista' do que como pesquisa objetiva da realidade presente", já que "o poderoso ímã da literatura interferia com a tendência sociológica, dando origem àquele gênero misto de ensaio", que seria "uma forma bem brasileira de investigação e descoberta do Brasil" (CANDIDO, 1967, p. 153).

Neste estilo fortemente literário, portanto, o sociólogo Gilberto Freyre propugna uma visão de Brasil como sendo a de um país de tradição eminentemente feudal. No prefácio à primeira edição de Casa-grande \& senzala, obra que, nas palavras do autor, descreve o "desenvolvimento da família patriarcal - agrária e escravocrata - no nosso país" (FREYRE, 2002, p. 499), cuja formação e consolidação foi “a seu modo, feudal” (2002, p. 504), Freyre afirma:

A casa-grande venceu no Brasil a Igreja, nos impulsos que esta a princípio manifestou para ser a dona da terra. Vencido o jesuíta, o senhor de engenho ficou dominando a colônia quase sozinho. O verdadeiro dono do Brasil. Mais do que os vice-reis e os bispos. A força concentrou-se nas mãos dos senhores rurais. Donos das terras. Donos dos homens. Donos das mulheres. Suas casas representam esse imenso poderio feudal (FREYRE, 2002, p. $15)$.

O etos da casa-grande no Brasil, embora associado "particularmente ao engenho de cana, ao patriarcalismo nortista", não se deve ser considerado "expressão exclusiva do açúcar, mas da monocultura escravocrata e latifundiária em geral: criou-se no Sul o café tão brasileiro como no Norte o açúcar” (FREYRE, 2002, p. 20-21). E, efetivamente, o sociólogo conclui que

Percorrendo-se a antiga zona fluminense e paulista dos cafezais, sente-se nos casarões em ruínas, nas terras ainda sangrando das derrubadas e dos processos de lavoura latifundiária, a expressão do mesmo impulso econômico que em Pernambuco criou as casas-grandes de Megaípe, de Noruega, de Monjope, de Gaipió, de Morenos... (FREYRE, 2002, p. 20-21).

Claro está que Freyre reconhece no contexto da economia brasileira baseada na "monocultura latifundiária e escravocrata" a influência, também, do "capitalismo burguês" (FREYRE, 2002, p. 506), conforme afirma no prefácio à sexta edição de Casa-grande \& senzala, de 1949:

Em torno daquele complexo - o monocultor; escravocrata e patriarcal e, ao seu modo, feudal, completado pela presença contraditória, no meio de sistema já arcaico de domínio da terra, da figura moderna do capitalista, ou do intermediário, armazenário ou comissário do açúcar, do algodão, do cacau ou do café - é que se processou o desenvolvimento do Brasil como nação... (FREYRE, 2002, p. 507). 


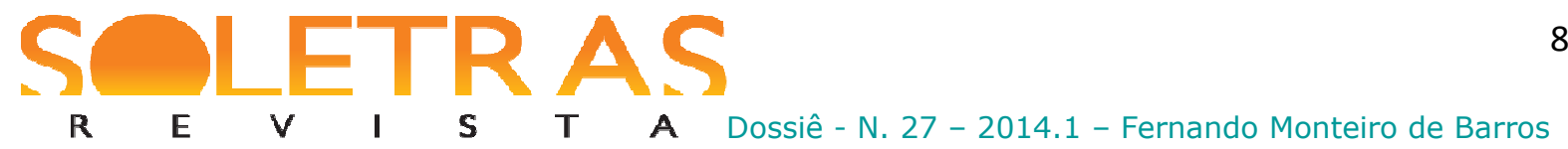

Mas, na obra, o que acaba prevalecendo mesmo é o recorte aristocrático e senhorial do Brasil. Nas palavras de Stuart B. Schwartz, "a ênfase que Gilberto Freyre colocava nas relações sociais patriarcais fazia eco com a interpretação 'feudal' do passado brasileiro, que ele compartilhava com Oliveira Vianna" (SCHWARTZ, 2002, p. 911). E, para a tese que queremos desenvolver aqui, interessa-nos sobremaneira constatar que, em Freyre, se faz perceber a influência do estilo artístico e literário do final do século XIX denominado Decadentismo (LARRETA; GIUCCI, 2002, p. 725). Segundo Elide Rugai Bastos, “o tema da decadência aparece reiteradamente na obra de Gilberto Freyre" (BASTOS, 2002, p. 815). Com efeito, o mote que perpassa a obra de estreia do sociólogo pernambucano é o da “decadência da aristocracia rural” (CANDIDO, 1967, p. 145), que, na visão de Antonio Candido, faz com que Freyre pareça "um sociólogo antes conservador" (CANDIDO, 1967, p. 158), possivelmente responsável pelo fato de que "no Nordeste do país as influências modernistas foram contrabalançadas por um forte movimento tradicionalista, cujo programa foi renovar mediante uma espécie de explosão do regionalismo" (CANDIDO, 2004, p. 99). Dentro deste escopo, como por sua vez afirma Alfredo Bosi, avulta um "José Lins do Rego e sua poética feita de lugares-comuns veristas", afetados por um "neo-romantismo nostálgico, afim à visão do mundo de Gilberto Freyre” (BOSI, 1999, p. 398), cuja obra, já na visão de Luciana Stegagno Picchio, seria perpassada por certa "saudade do bom tempo antigo" (PICCHIO, 1997, p. 528). E, nas palavras de Massaud Moisés, "nem o romance social conseguiu vencer o apelo do passadismo que o magistério de Gilberto Freyre pressupunha" (MOISÉS, 1989, p. 178).

Freyre, leitor de autores como Joris Karl Huysmans, Walter Pater e Marcel Proust, afigura-se como um "observador nostálgico do mundo dos senhores de engenho e da progressiva decadência de sua região com o analista dos limites históricos de uma modernidade que estava chegando ao Brasil" (LARRETA; GIUCCI, 2002, p. 731). Assim como nos romances decadentistas, há em Casa-grande \& senzala certa "crítica à cidade moderna" (BASTOS, 2002, p. 808), já que, conforma assinala Elide Rugai Bastos, “é constante na obra freyriana a invocação da tese: no passado existia uma unidade harmônica que é rompida pela modernização - da cidade, da casa, das relações sociais", e, assim, na visão freyriana de Brasil, "a cidade em desagregação figura a decadência do patriarcado" (BASTOS, 2002, p. 809). Freyre fala do "barato cosmopolitismo em que entre nós se vai dissolvendo o espírito nacional" (BASTOS, 2002, p. 809-810), consistente com o dado de que "a ideia freyriana de decadência está estruturalmente associada à perda de tradições" 


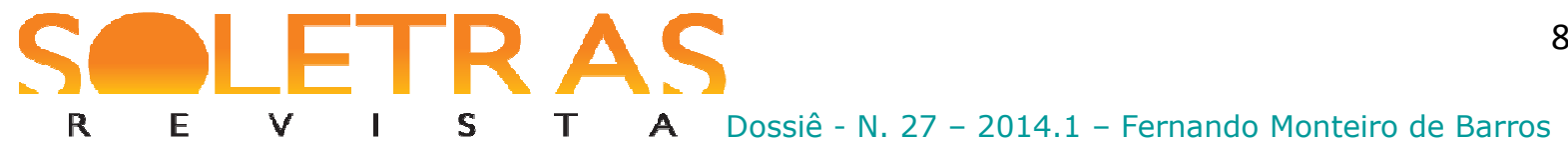

(BASTOS, 2002, p. 816). Conforme explica Maria Alice Rezende de Carvalho, "a semântica da ruptura foi, assim, o largo estuário no qual se encontraram as diferentes críticas à formação do Brasil, identificando nas 'casas grandes' elogiadas por Freyre, a última trincheira do passado, de um mundo em vias de extinção" (CARVALHO, 2002, p. 898). Os temas de "um mundo em vias de extinção" e da "decadência da aristocracia face à modernidade burguesa" constituem, sabidamente, elementos basilares da poética decadentista.

Foi José Guilherme Merquior “quem primeiro registrou a fundamental relação entre o decadentismo e o modernismo na trilogia freyriana", pois, na obra de Gilberto Freyre, Merquior aponta "a presença da cultura decadentista fim-de-século" (GIUCCI; LARRETA, 2002, p. 944). Nas palavras do próprio crítico literário, dentre os elementos formadores do pensamento do sociólogo pernambucano, "era notável a presença, desde o jovem Gilberto, de motivos pertencentes à cultura decadentista finissecular" (MERQUIOR, 2002, p. 1045), uma vez que, assim como para os escritores decadentistas europeus, "o antiburguesismo de Gilberto era de fato uma atitude estética, dirigida principalmente contra a moral vitoriana e a razão positivista" (MERQUIOR, 2002, p. 1045). E Merquior conclui que "dadas essas raízes vitalistas e esteticistas [Pater e Wilde], não é de admirar que o livro com que o Brasil inaugurou a radiografia de seu passado íntimo fosse obra de um sociólogo convencido da primazia cognitiva da arte literária" (MERQUIOR, 2002, p. 1046). O Decadentismo, com efeito, apresenta todas essas questões, conforme afirma Latuf Mucci sobre este movimento artístico-literário:

Criou-se, então, um elo paradoxal entre aristocracia e anarquismo, pois os artistas decadentistas - aristocráticos de cepa ou por pretensão, mas, em todo caso, criando personagens todas aristocráticas que vivem e circulam em palácios - se revoltaram contra a burguesia industrial (MUCCI, 1994, p. $30)$.

O Decadentismo, por sua vez, apresenta estreita relação com o Romantismo gótico, conforme sustenta Luiz Edmundo Bouças Coutinho, ao afirmar que

[...] no final do século XIX, o fantasma romântico estimulou a estética decadentista a acionar um estado de revolta contra os pressupostos positivistas, a assumir uma atitude contestatória que ganharia a forma de um tardio mal du siècle, imprimindo, nas impostações teatrais do dandy, um egotismo double do culto do eu. (COUTINHO, 2010, p. 17).

Assim, dentro deste âmbito da literariedade e da junção do Gótico com o Decadentismo, vemos na obra de Freyre, curiosamente, trechos em que a casa-grande brasileira mostra marcas de uma intertextualidade explícita com os castelos de Horace Walpole e Ann Radcliffe, conforme o trecho a seguir: 


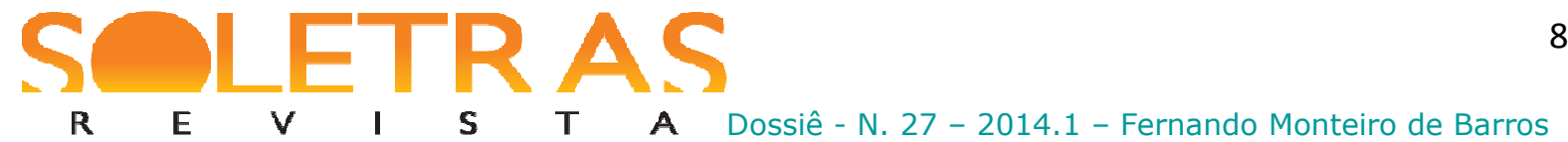

O costume de se enterrarem os mortos dentro de casa - na capela, que era uma puxada da casa - é bem característico do espírito patriarcal de coesão de família. Os mortos continuavam sob o mesmo teto que os vivos. Entre os santos e as flores devotas. Santos e mortos eram afinal parte da família (FREYRE, 2002, p. 16).

Tal convivência entre os vivos e os mortos dentro do mesmo espaço acaba por conferir à casa-grande freyriana certo aspecto lendário de castelo mal-assombrado:

Por segurança e precaução contra os corsários, contra os excessos demagógicos, contra as tendências comunistas dos indígenas e dos africanos, os grandes proprietários, nos seus zelos exagerados de privativismo, enterraram dentro de casa as jóias e o ouro do mesmo modo que os mortos queridos. Os dois fortes motivos das casas-grandes acabarem sempre mal-assombradas com cadeiras de balanço se balançando sozinhas sobre tijolos soltos que de manhã ninguém encontra; com barulho de pratos e copos batendo de noite nos aparadores; com almas de senhores de engenho aparecendo aos parentes ou mesmo estranhos pedindo padresnossos, aves-marias, gemendo lamentações, indicando lugares com botijas de dinheiro (FREYRE, 2002, p. 17-18).

Dentro desta voltagem, na qual o sobrenatural se faz presente, nosso sociólogo afirma que, na casa-grande, "são quase sempre almas penadas de senhores de engenho que aparecem pedindo padres-nossos e ave-marias" (FREYRE, 2002, p. 18), uma vez que "os malassombrados costumam reproduzir as alegrias, os sofrimentos, os gestos mais característicos da vida nas casas-grandes" (FREYRE, 2002, p. 19), conforme o extraordinário trecho que transcrevemos abaixo, que, para nós, evidencia em Gilberto Freyre a presença de um indiscutível Gótico brasileiro:

Os mal-assombrados das casas-grandes se manifestam por visagens e ruídos que são quase os mesmos por todo o Brasil. Pouco antes de desaparecer, estupidamente dinamitada, a casa-grande de Megaípe, tive ocasião de recolher, entre os moradores dos arredores, histórias de assombrações ligadas ao velho solar do século XVII. Eram barulhos de louça que se ouviam na sala de jantar; risos alegres e passos de dança na sala de visita; tilintar de espadas; ruge-ruge de sedas de mulher; luzes que se acendiam e se apagavam de repente por toda a casa; gemidos; rumor de correntes se arrastando; choro de menino; fantasma do tipo cresce-míngua. Assombrações semelhantes me informaram no Rio de Janeiro e em São Paulo povoar os restos de casas-grandes do vale do Paraíba (FREYRE, 2002, p. 18-19).

Bridget M. Marshall ressalta que, a respeito do Gótico do sul dos Estados Unidos, "a arquitetura dessas grandes plantations, em seu aspecto físico, também funciona como metáfora, ao fazer alusão à história sombria dessas construções", uma vez que as narrativas góticas "tipicamente incluem um pano de fundo que revela a verdadeira história desses casarões, que inclui tortura, estupro e outros crimes cometidos contra os escravos negros por 


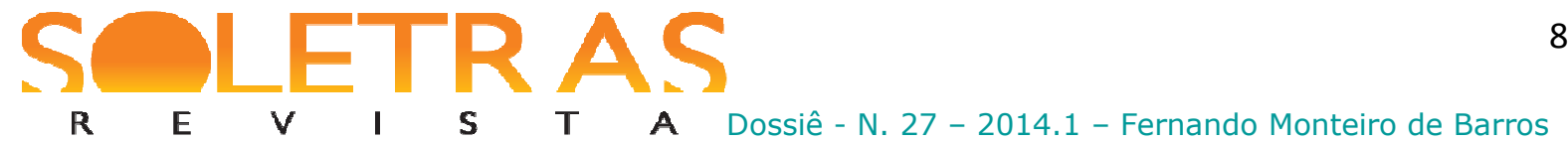

seus senhores brancos", sendo que "os casarões das plantations escravistas, assim como sua contraparte na literatura gótica, frequentemente apresentam câmaras secretas e mesmo espaços usados especificamente para a punição dos escravos" (MARSHALL, 2013, p. 7). Tais aspectos do Southern Gothic também se fazem presentes no construto freyriano da casagrande brasileira:

Refere uma tradição nortista que um senhor de engenho mais ansioso de perpetuidade não se conteve: mandou matar dois escravos e enterrá-los nos alicerces da casa. O suor e às vezes o sangue dos negros foi o óleo que mais do que o de baleia ajudou a dar aos alicerces das casas-grandes sua consistência quase que de fortaleza (FREYRE, 2002, p. 15).

Freyre continua a dizer que "noutras casas-grandes só se têm desencavado, do chão, ossos de escravos, justiçados pelos senhores e mandados enterrar no quintal, ou dentro de casa, à revelia das autoridades" (FREYRE, 2002, p. 18). E tais crimes de horror se estendem até mesmo aos membros da família, em histórias dignas de Edgar Allan Poe: "eram senhores, os das casas-grandes, que mandavam matar os seus próprios filhos. Um desses patriarcas, Pedro Vieira, já avô, por descobrir que o filho mantinha relações com a mucama de sua predileção, mandou matá-lo pelo irmão mais velho" (FREYRE, 2002, p. 18).

Conforme assinala Eduardo Portella, em Casa-grande \& senzala "não é difícil constatar que a alta modernidade, a modernidade das Luzes, da razão unânime, imperativa e categórica, sofre aqui alguns revezes" (PORTELLA, 2002, p. XXI), uma vez que Gilberto Freyre "deixa de lado a compreensão territorial da modernidade, a cartografia da razão hegemônica, e finca outras fronteiras, desenha novos mapas" (PORTELLA, 2002, p. XXI), reverberando o que acontece no Romantismo gótico e no Decadentismo. Karl Marx chegou a afirmar, acerca da tradição face à modernidade, que "o Antigo Regime é o pecado oculto do Estado Moderno. A luta contra a situação política presente da Alemanha é a luta contra o passado dos povos modernos, e as reminiscências deste passado sempre vêm importuná-los" (MARX apud MATOS, 1995, p. 39), ao que Walter Benjamin acrescenta: "a modernidade carrega a antiguidade como um mau espírito (wie einen $A l b$ ) que teria vindo importuná-la em seu sono. $A l b$ ou Alp: mau demônio, fantasma que à noite vem se postar no peito de quem dorme e provoca pesadelos (Alptraum)" (MATOS, 1995, p. 72-73). O Gótico, com efeito, deixa entrever o que Marx afirmara no 18 Brumário: "a tradição de todas as gerações mortas pesa como um mau espírito (wie ein Alp) sobre o cérebro dos vivos” (MATOS, 1995, p. 113).

Assim como grande parte das narrativas góticas se passa no mundo mediterrâneo $(O$ castelo de Otranto, de Horace Walpole, $O$ italiano, de Ann Radcliffe, $O$ monge de Matthew Lewis, Fragmento de um romance, de Lord Byron), parecendo estabelecer uma contraposição SOLETRAS, N. 27 (jan.-jun. 2014) 


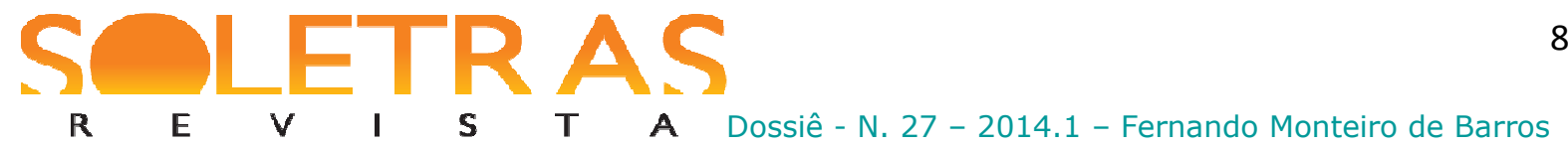

entre o que se poderia desenhar como sendo uma germanicidade racionalista e uma mediterraneidade irracionalista, tal viés é analisado por Elide Rugai Bastos no pensamento de Gilberto Freyre, como leitor que era de José de Ortega y Gasset. O pensador espanhol, de fato, discute sobre "a especificidade dos povos mediterrâneos face aos germânicos": "o germânico tem como instrumento o conceito; o mediterrâneo a impressão" (BASTOS, 2002, p. 813). Ao apontar "a diversidade dos povos mediterrâneos", Ortega y Gasset, ainda segundo Bastos, "quer mostrar não estar presente na formação dos mesmos o racionalismo burguês" e "acentua a predominância do sensualismo no caráter ibérico, resultado do encontro entre as culturas oriental e ocidental". A cultura mediterrânea seria "herdeira de Creta e não da cultura helênica, sendo que "em Creta desemboca a civilização oriental e se inicia outra que não é grega”. São, assim, povos marcados mais pela sensibilidade do que pela razão" (BASTOS, 2002, p. 812). Assim, dentro desta premissa, Gilberto Freyre, a partir de sua leitura de Ortega y Gasset, seguiria a mesma linha de raciocínio: "vale lembrar que a tese dos estilos de vida dos povos desenvolvida pelo pensador espanhol atravessa a reflexão freyriana" (BASTOS, 2002, p. 812).

Além da relação entre a casa-grande freyriana e o castelo gótico, também arriscamos a tese de que tal espaço, tanto em Freyre quanto no Gótico inglês e no Southern Gothic, constitui, pelo seu caráter de ruína, uma alegoria da tradição. Conforme afirma Latuf Mucci, a respeito da estética decadentista, irmã-gêmea do Gótico (COUTINHO, 2010, p. 17), “a alegoria talvez se constitua na herança mais marcante deixada pelo Decadentismo, que denunciou a ruína, cultuando o artifício, que parece mais perene que o natural” (MUCCI, 1994, p. 62). Referindo-se ao pensamento de Walter Benjamin, que em sua tese sobre o drama barroco alemão explorou a relação entre alegoria e ruína, Latuf Mucci ressalta que "dentro da estética da alegoria, a obra de arte é vista como ruína, ruína de algo que não houve, uma vez que a literatura versa sobre um mundo ficcional” (MUCCI, 1994, p. 63). Tal afirmação sustenta a nossa presente reflexão se pensamos a casa-grande freyriana como um constructo no qual a ficcionalidade do literário, como vimos, desempenha um papel fundamental, no enquadramento que tal espaço recebe na visão de mundo de Gilberto Freyre, fortemente marcada por influências da estética decadentista e eivada de elementos pertencentes ao imaginário do Gótico. Nas palavras do próprio Freyre, "vêem-se ainda em Pernambuco as ruínas do grande solar dos Barões das Mercês...” (FREYRE, 2002, p. 15). Analogamente, no Gótico inglês, David Punter e Glennis Byron reconhecem que o castelo mal-assombrado avulta como "um sinal de antiguidade, de uma vida que precedeu a nossa, mas que parece 


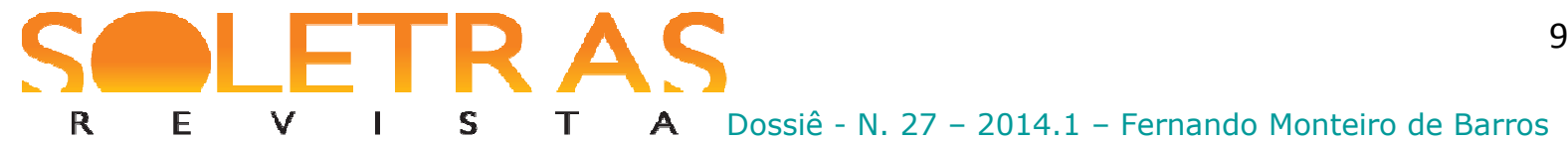

nunca ter ido embora, e como tal refere-se tanto a um aspecto do inconsciente quanto a um momento histórico do feudalismo" (PUNTER; BYRON, 2004, p. 262), já que o castelo "nos coloca diante de um excesso de poder patriarcal, enquanto que ao mesmo tempo nos transmite que mesmo os monumentos mais pungentes da grandiosidade humana tornam-se, ou talvez sempre tenham sido, ruínas" (PUNTER; BYRON, 2004, p. 262). Retomando as reflexões de Mucci, "o Decadentismo rompe com a representação simbólica, inaugurando a estética da alegoria: o belo em ruínas ou a ruína do belo, prefaciando o cenário de cinzas da modernidade e da pós-modernidade" (MUCCI, 1994, p. 61). Etimologicamente, alegorizar é "dizer o outro", "falar uma coisa para significar outra" (MUCCI, 1994, p. 61-62). Mas, na tese de Walter Benjamin sobre o Barroco, publicada em 1928, a alegoria prende-se a uma visão de mundo decaído e privado de valores transcendentais, em que só restam destroços e ruínas:

Quando, com o drama barroco, a história penetra no palco, ela o faz enquanto escrita. A palavra história está gravada, com os caracteres da transitoriedade, no rosto da natureza. A fisionomia alegórica da naturezahistória, posta no palco pelo drama, só está verdadeiramente presente como ruína. Como ruína, a história se fundiu sensorialmente com o cenário. Sob essa forma, a história não constitui um processo de vida eterna, mas de inevitável declínio. Com isso, a alegoria reconhece estar além do belo. As alegorias são no reino dos pensamentos o que são as ruínas no reino das coisas. Daí o culto barroco das ruínas (BENJAMIN, 1984, p. 199-200).

Benjamin continua a afirmar que "em sua artificialidade, essas ruínas aparecem como o último legado de uma Antiguidade que no solo moderno só pode ser vista, de fato, como um pitoresco monte de escombros" (BENJAMIN, 1984, p. 200), e conclui: "o que jaz em ruínas, o fragmento significativo, o estilhaço: essa é a matéria mais nobre da criação barroca" (BENJAMIN, 1984, p. 200), pois "a obra de arte barroca quer unicamente durar, e prende-se com todas as forças ao eterno" (BENJAMIN, 1984, p. 202). Sobre o Barroco e a relação que este mantém com a tradição, que consideramos análoga à do Gótico e à do Decadentismo, afirma Alfredo Bosi que "há um nexo entre o Barroco hispânico-romano e toda uma realidade social e cultural que se inflecte sobre si mesma ante a agressão da modernidade burguesa, científica e leiga" (BOSI, 1999, p. 29). A alegoria da tradição face ao moderno, em nossa opinião, da mesma forma como no Barroco, também se faz perceber fantasmaticamente no Gótico, com seus espaços mal-assombrados, e transgressoramente no Decadentismo, que, inspirado em Baudelaire, utiliza em sua estética os avatares da tradição aristocrática como uma espécie de afronta ao prosaísmo burguês.

Em todas essas três estéticas predomina a franja fúnebre da melancolia, que, para Giorgio Agamben, traduz-se em uma "capacidade fantasmática de fazer aparecer como 


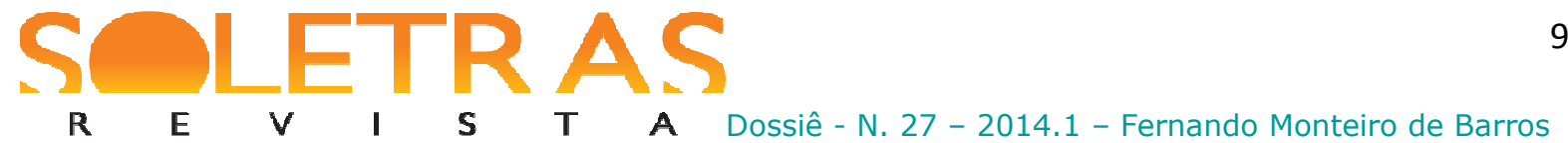

perdido um objeto inapreensível", pois "cobrindo o seu objeto com os enfeites fúnebres do luto, a melancolia lhes confere a fantasmagórica realidade do perdido" (AGAMBEN, 2007, p. 45). Nossa tese de um enquadramento gótico na casa-grande freyriana, espaço que avulta como verdadeiro fetiche para o sociólogo pernambucano, é também possivelmente sustentada pelo pensamento teórico de Agamben, ao dizer que "assim como o fetiche é, ao mesmo tempo, o sinal de algo e sua ausência, e deve a tal contradição o próprio estatuto fantasmático, assim o objeto da intenção melancólica é, contemporaneamente, real e irreal, incorporado e perdido, afirmado e negado" (AGAMBEN, 2007, p. 46). Como elemento factual e histórico, objeto de investigação sociológica, a casa-grande freyriana tem um lastro no real, mas que, ambiguamente, convive com o irreal da literariedade gótica, que recobre seu constructo como fetiche e alegoria de um passado extinto, ao qual o sociólogo alude nostálgica e melancolicamente. Paradoxal, a casa-grande de Gilberto Freyre avulta como um verdadeiro "lugar paratópico" (MAINGUENEAU, 2006, p. 129), com seu alicerce ao mesmo tempo no real e no irreal. Conforme sinaliza Dominique Maingueneau, a paratopia é uma "localidade paradoxal, que não é ausência de lugar, mas uma difícil negociação entre o lugar e o nãolugar" (2006, p. 68).

Alegoria de um passado perdido, a casa-grande de Freyre comparece, no cenário modernizante dos anos 30 do século $\mathrm{XX}$ como um verdadeiro fantasma, consoante a afirmação de Giorgio Agamben:

A perda imaginária que se apodera tão obsessivamente da intenção melancólica não tem objeto real algum, porque sua fúnebre estratégia está voltada para a impossível captação do fantasma. O objeto perdido não é nada mais que a aparência que o desejo cria para o próprio cortejo do fantasma... (AGAMBEN, 2007, p. 53).

Concluímos afirmando que, se "a primeira manifestação literária do gênero fantástico foi o romance gótico inglês, que inicia sua trajetória com $O$ castelo de Otranto (1764), de Horace Walpole" (ROAS, 2014, p. 48), Casa-grande \& senzala foi um marco determinante para a constituição, no campo da imagética literária, do modelo topográfico do Gótico brasileiro, que terá sua continuidade nas narrativas melancólicas, fantasmáticas e alegóricas de Cornélio Penna e Lúcio Cardoso.

\section{Referências bibliográficas:}

AGAMBEN, Giorgio. Estâncias. A palavra e o fantasma na cultura ocidental. Trad. Selvino José Assmann. Belo Horizonte: Ed. UFMG, 2007. 
BASTOS, Elide Rugai. Gilberto Freyre: um escritor ibérico. In: FREYRE, Gilberto. Casagrande \& senzala. Edição crítica coordenada por Guillermo Giucci, Enrique Rodriguez Larreta e Edson Nery da Fonseca. Madrid; Barcelona; La Habana; Lisboa; Paris; México; Buenos Aires; São Paulo; Lima; Guatemala; San José: ALLCA XX, 2002 (Coleção Archivos, $55)$.

BENJAMIN, Walter. Origem do drama barroco alemão. Trad. apres. e notas Sérgio Paulo Rouanet. São Paulo: Brasiliense, 1984.

BOSI, Alfredo. História concisa da literatura brasileira. 36.ed. São Paulo: Cultrix, 1999.

CANDIDO, Antonio. Iniciação à literatura brasileira. 4.ed. Rio de Janeiro: Ouro Sobre Azul, 2004.

Literatura e sociedade. 2.ed. São Paulo: Companhia Editora Nacional, 1967.

CARVALHO, Maria Alice Rezende de. Casa-grande \& senzala e o pensamento social brasileiro. In: FREYRE, Gilberto. Casa-grande \& senzala. Edição crítica coordenada por Guillermo Giucci, Enrique Rodriguez Larreta e Edson Nery da Fonseca. Madrid; Barcelona; La Habana; Lisboa; Paris; México; Buenos Aires; São Paulo; Lima; Guatemala; San José: ALLCA XX, 2002 (Coleção Archivos, 55).

COUTINHO, Luiz Edmundo Bouças. Romantismo/Decadentismo: gêmeos sinistros?. In: ;FARIA, Flora de Paoli (Orgs.). Faces rituais da poesia. Rio de Janeiro: Confraria do Vento, 2010.

ELLIS, Jay. On Southern Gothic Literature. In: (Ed.). Southern gothic literature (Critical insights). Ipswich, Massachussetts: Salem Press; Amenia, NY: Grey House Publishing, 2013.

FONSECA, Edson Nery da. Casa-grande \& senzala como obra literária. In: FREYRE, Gilberto. Casa-grande \& senzala. Edição crítica coordenada por Guillermo Giucci, Enrique Rodriguez Larreta e Edson Nery da Fonseca. Madrid; Barcelona; La Habana; Lisboa; Paris; México; Buenos Aires; São Paulo; Lima; Guatemala; San José: ALLCA XX, 2002 (Coleção Archivos, 55).

FREYRE, Gilberto. Casa-grande \& senzala. Edição crítica coordenada por Guillermo Giucci, Enrique Rodriguez Larreta e Edson Nery da Fonseca. Madrid; Barcelona; La Habana; Lisboa; Paris; México; Buenos Aires; São Paulo; Lima; Guatemala; San José: ALLCA XX, 2002 (Coleção Archivos, 55).

GIUCCI, Guillermo; LARRETA, Enrique Rodríguez. Casa-grande \& senzala. História da recepção. In: FREYRE, Gilberto. Casa-grande \& senzala. Edição crítica coordenada por Guillermo Giucci, Enrique Rodriguez Larreta e Edson Nery da Fonseca. Madrid; Barcelona; La Habana; Lisboa; Paris; México; Buenos Aires; São Paulo; Lima; Guatemala; San José: ALLCA XX, 2002 (Coleção Archivos, 55).

LARRETA, Enrique Rodríguez; GIUCCI, Guillermo. Casa-grande \& senzala: os materiais da imaginação histórica". FREYRE, Gilberto. Casa-grande \& senzala. Edição crítica coordenada por Guillermo Giucci, Enrique Rodriguez Larreta e Edson Nery da Fonseca. 
Madrid; Barcelona; La Habana; Lisboa; Paris; México; Buenos Aires; São Paulo; Lima; Guatemala; San José: ALLCA XX, 2002 (Coleção Archivos, 55).

MAINGUENEAU, Dominique. Discurso literário. Trad. Adail Sobral. São Paulo: Contexto, 2006.

MARSHALL, B. M. Defining Southern Gothic.In ELLIS, Jay. (Ed.). Southern gothic literature (Critical insights).Ipswich, Massachussetts: Salem Press; Amenia, NY: Grey House Publishing, 2013.

MATOS, Olgária C. F. Os arcanos do inteiramente outro: a Escola de Frankfurt, a melancolia e a revolução. 2.ed. São Paulo: Brasiliense, 1995.

MERQUIOR, José Guilherme. Na casa grande dos oitenta. In: FREYRE, Gilberto. Casagrande \& senzala. Edição crítica coordenada por Guillermo Giucci, Enrique Rodriguez Larreta e Edson Nery da Fonseca. Madrid; Barcelona; La Habana; Lisboa; Paris; México; Buenos Aires; São Paulo; Lima; Guatemala; San José: ALLCA XX, 2002. (Coleção Archivos, $55)$.

MOISÉS, Massaud. História da literatura brasileira. São Paulo: Cultrix, 1989 (v. V: Modernismo).

MUCCI, Latuf Isaías. Ruína \& simulacro decadentista: uma leitura de Il piacere, de D’Annunzio. Rio de Janeiro: Tempo Brasileiro, 1994.

OLIVEIRA, Alberto. Melhores poemas. Seleção de Sânzio de Azevedo. São Paulo: Global; Rio de Janeiro: Academia Brasileira de Letras, 2007.

PICCHIO, Luciana Stegagno. História da literatura brasileira. Trad. Pérola de Carvalho e Alice Kyoko. Rio de Janeiro: Nova Aguilar, 1997.

PORTELLA, Eduardo. Gilberto Freyre: as impurezas da modernidade. In: FREYRE, Gilberto. Casa-grande \& senzala. Edição crítica coordenada por Guillermo Giucci, Enrique Rodriguez Larreta e Edson Nery da Fonseca. Madrid; Barcelona; La Habana; Lisboa; Paris; México; Buenos Aires; São Paulo; Lima; Guatemala; San José: ALLCA XX, 2002 (Coleção Archivos, 55).

PUNTER, David; BYRON, Glennis.The Gothic. Oxford: Blackwell Publishing, 2004.

ROAS, David. A ameaça do fantástico: aproximações teóricas. Trad. Julián Fuks. São Paulo: Editora Unesp, 2014.

SCHNAIDERMAN, Boris. "Prefácio". In: Teoria da literatura: formalistas russos. 3. ed. Porto Alegre: Globo, 1976.

SCHWARTZ, Stuart B. Gilberto Freyre e a história colonial: uma visão otimista do Brasil. In: FREYRE, Gilberto. Casa-grande \& senzala. Edição crítica coordenada por Guillermo Giucci, Enrique Rodriguez Larreta e Edson Nery da Fonseca. Madrid; Barcelona; La Habana; Lisboa; Paris; México; Buenos Aires; São Paulo; Lima; Guatemala; San José: ALLCA XX, 2002 (Coleção Archivos, 55). 


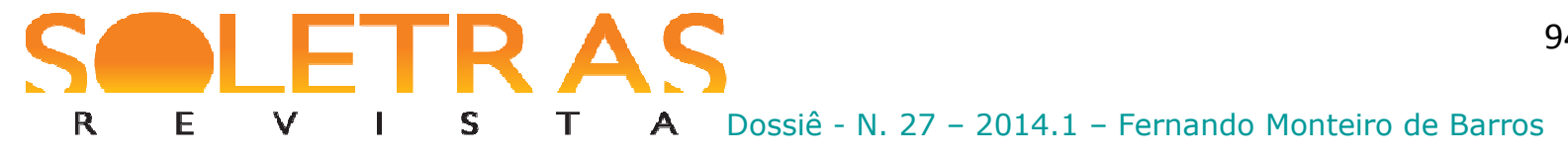

\title{
From castle to big house: Brazilian Gothic in Gilberto Freyre
}

\begin{abstract}
Taking the topography of the English Gothic novel as its key element, expressed in the haunted castle, we establish a theory of what might be called Brazilian Gothic, expressed in the topography of the big house according to the construct established by Brazilian sociologist Gilberto Freyre in The masters and the slaves, in which one finds an enormous presence of the literary. The recent theories on Southern Gothic, according to which the scars of slavery constitute its main aspect, corroborate our thesis on Freyre's big house, which, phantasmatically and allegorically, looms as a paratopic setting, where sociological reality mingles with the irreality of literary imagery.
\end{abstract}

Key words: Brazilian Gothic. Tradition and modernity.Phantasm and Allegory.

Recebido em: 13 de maio de 2014 .

Aprovado em: 29 de setembro de 2014. 